\title{
1 Future Heating and Cooling Degree Days for Belgium under a high-end
}

\section{2 climate change scenario}

\section{Abstract}

4 The local outdoor climate and building characteristics influence the energy use of a building to an important extent. To design energy efficient and climate robust buildings, it is important to get insights into the energy demand over the building's service life from the early design phase onwards. This paper presents an overview of the different variants of the heating and cooling degree day method. A convection-permitting climate model is furthermore used to obtain heating and cooling degree days (for a baseline temperature of $18^{\circ} \mathrm{C}$ ) for the RCP 8.5 (high-end) climate change scenario for Belgium on a high-resolution grid of $2.8 \mathrm{~km}$. Area of focus for this paper is Belgium. The results demonstrate a decrease of the HDD with 27\% between 1976-2004 (3189 HDD) and 2070-2098 (2337 HDD). In contrast, the CDD were found to increase with a factor 2.4 from 167 CDD to 401 CDD in the same timeline. Smaller reductions in average HDD were moreover found in urban areas compared to rural areas. For the CDD, a higher absolute increase was found for urban areas and the Northeast of Belgium. 
14

\section{Introduction}

The local environmental conditions of a building influence its energy use to an important extent. As buildings have a relatively long service life, new buildings and many of the existing ones will face climate change. Representative Concentration Pathways (further abbreviated as RCP) are defined by the Intergovernmental Panel on Climate Change (IPCC) fifth assessment report as scenarios for different trajectories of primarily the concentrations of greenhouse gases (GHG) [1]. Four RCPs are defined, i.e. RCP 2.6, RCP4.5, RCP6.0 and RCP 8.5 which refer to the radiative forcing established by the GHG emissions in the year 2100 relative to the preindustrial values [1]. The RCP 2.6 scenario is a mitigation scenario where the increase of global mean temperature is likely below $2^{\circ} \mathrm{C}$, linked to a decrease of GHG emissions by mid-century. The RCP 4.5 and 6.0 are two intermediate stabilization pathways characterised by a stabilisation of the emissions shortly after 2100 . The RCP 8.5 scenario is a high-end pathway characterised by increasing GHG emissions. The latter is hence a worstcase scenario and is considered in this paper.

Worldwide, a decrease in the need for heating and an increase in the need for cooling are expected [2,3]. A median climate change scenario is expected to lead to an increase by $74 \%$ to $118 \%$ by 2100 for cooling and a decrease of $0.7 \%$ per year for heating [3]. The effect of climate change on the heating and cooling demand of buildings, however, highly depends on the location of the building determining the climate conditions and on the building characteristics [4]. To design climate robust buildings, it is important to get insights into the influence of climate change on the heating and cooling demand from the early design phase onwards when important design decisions are taken [5-7]. With climate robust buildings we refer to nearly zero energy buildings in line with the EU requirements by 2020 [8] with a good thermal comfort of which the building energy performance is least sensitive to the influence of climate change.

During the early design stage, heating and cooling degree days (further abbreviated as HDD and CDD respectively) are often used to estimate the heating and cooling demand [9-11] as the use of energy simulation tools is often too complex in this stage [6]. The design tool of Trigaux et al. [10] uses degree days to assess the heating demand of buildings in the master planning phase of neighbourhoods. Similarly, the research of De Rosa et al. [11] presents a simple dynamic model to simulate the heating and cooling energy consumption of buildings based on degree days. Further, this methodology can be used to estimate energy consumption of buildings on 
41 a broader scale as done in the research of Isaac and van Vuuren [2] on a global scale. The degree days (further abbreviated as DD with unit ${ }^{\circ} \mathrm{d}$ ) method originates from the agricultural research domain where the knowledge about the variation in outdoor temperature was important [12]. DD are calculated as the deviation from a base temperature expressed in degree Celsius $\left({ }^{\circ} \mathrm{C}\right)[13,14]$ and typically accumulated over a year. Consequently, the extremity and duration of outdoor temperatures are both captured in this metric [15].

For Belgium, DD are typically calculated based on observations from weather stations (e.g. Uccle, situated in the centre of Belgium or Beerse, situated in the Northeast of Belgium close to the Dutch border). Hence, two challenges arise. First, the use of observational data does not allow future forecasts, except on the assumption that there is a similar trend of change as noticed in the past. Second, information is only available for a few locations. Hence, regional or local differences caused by for example topography or urban heat island effects are not represented.

The research of Spinoni et al. $[13,16]$ uses climate models to present and forecast HDD and CDD across Europe. Future projections for HDD and CDD are available $[16,17]$, however, based on climate data with a low spatial $(\sim 12.5 \mathrm{~km})$ and temporal resolution (daily scale) $[16,18]$. Consequently, regional and local variations are not or poorly represented and the daily scale jeopardises an accurate estimate of the DD $[9,19]$. The use of a climate model with a higher spatial resolution (e.g. $<4 \mathrm{~km}$ ) improves the representation of local temperature differences and is able to produce data with a higher temporal resolution (e.g. hourly resolution).

The goal of this paper is threefold. Firstly, an appropriate metric to represent the heating and cooling need of buildings in Belgium is presented. Secondly, HDD and CDD are calculated and presented for a future climate perspective (2069-2099). Thirdly, the calculated HDD and CDD are visualised for Belgium on a high-density grid (2.8 km spatial resolution). This paper presents HDD and CDD maps for Belgium for the current and future climate perspective considering the RCP8.5 climate change scenario using a high-resolution climate model (2.8 km grid spacing and hourly time resolution). A comparison is made with existing HDD and CDD maps/data.

The paper is structured as follows. Section 2 provides an overview of the degree day metric for heating and cooling needs in general and for Belgium in particular, including the evolution of these metrics over the past decades. Section 3 deals with future projections of the degree day metric, followed by a section about spatial representation linked to the climate models. Detailed information about the climate model and the 
methodology used in this paper is provided in section 5 . Section 6 presents the maps obtained followed by a discussion and conclusion section.

\section{Metrics for heating and cooling needs}

\subsection{Heating Degree Days: metric for heating need}

As mentioned in the introduction, HDD are calculated as the deviation from a base temperature expressed in degree Celsius $\left({ }^{\circ} \mathrm{C}\right)[13,14]$ and typically accumulated over a year. In the past, HDD were typically calculated on a daily basis. If for a given day, the mean temperature was $5^{\circ} \mathrm{C}$ lower than the base temperature, this leads to $5^{\circ} \mathrm{d}$. This calculation is repeated for the whole year that can be characterised for example by $2400^{\circ} \mathrm{d}$. Consequently, how cold and how long a winter is, can be captured in this metric. Degree days can be calculated based on hourly, daily (average daily temperatures or combined with minimum and maximum daily temperature) or monthly mean temperature data $[9,15]$. If a daily average temperature is above the base temperature, it is possible that several hours are below that base temperature leading for instance to a difference of $6^{\circ} \mathrm{h}$ or $0.25^{\circ} \mathrm{d}$. Monthly mean temperatures can even exclude several days with temperatures below the base temperature and induce important errors $[9,15]$. Degree days calculated based on hourly values are found to result in better estimates $[9,15]$ and are hence preferred if hourly temperature data are available.

\subsubsection{Overview HDD methods and evolutions in Belgium}

Although there is a uniform basic principle to calculate the number of HDD, several values are available for the number of HDD in Belgium. These are due to variations in the base temperature or temporal scale of weather data.

Since 1932, HDD are used in Belgium to predict the energy use for heating and predict the gas consumption [20]. Typically, HDD are calculated per month based on monthly (in the past) or daily mean temperature for a limited number of locations in Belgium. Since the end of the 1970s, the number of HDD is defined for a 'normal' year extracted from a 30-year period, currently updated every 5 years.

In international studies such as $[12,16,21-26]$, the base temperature is the reference indoor temperature. Still these lead to differences in HDD as the temperature setpoint differ. The research of Conradie [12] uses a base temperature of $18^{\circ} \mathrm{C}$ for South-Africa. The research of Spinoni $[13,16]$ uses a base temperature of $15.5^{\circ} \mathrm{C}$ for 
Europe. In the research of De Rosa et al. [11], situated in Italy, the base temperature is set to $18.3^{\circ} \mathrm{C}$, the internal temperature setpoint for heating. The research of Chiesa [23] uses a base temperature of $20^{\circ} \mathrm{C}$ for Italy. The research of Meng and Mourshed [22] presents a mean base temperature of $16.7^{\circ} \mathrm{C}$ for seven types of nonresidential buildings ranging from $12.8^{\circ} \mathrm{C}$ for storage buildings to $17.7^{\circ} \mathrm{C}$ for clubs and community centres situated in Cardiff (UK). The research of Papakostas and Kyriakis [24] refers to $18.3^{\circ} \mathrm{C}$ as standard temperature, but the authors stress that this leads to an overestimation of HDD as solar and internal gains will balance part of the heat losses. Consequently, in their study for Athens and Thessaloniki (Greece), HDD are calculated with base temperatures varying from 10 to $20^{\circ} \mathrm{C}$ per $0.5^{\circ} \mathrm{C}$. The ASHRAE book of fundamentals refers to $10^{\circ} \mathrm{C}$ and $18.3^{\circ} \mathrm{C}$ as most commonly used base temperatures [26]. In the Belgian context, a second temperature is often used for the calculation of HDD leading to a double base temperature (e.g. $\left.15^{\circ} \mathrm{C} / 18^{\circ} \mathrm{C}\right)[20,27]$. The second temperature refers to the "space and time average daily indoor temperature", i.e. the temperature to be reached by heating, while the first one is the average daily temperature of which it is assumed that no heating is required when exceeded [27]. This temperature is typically below the thermal comfort temperature as internal and solar gains will further increase the indoor temperature and so reduce the total heating demand of the building [27]. This temperature moreover defines the duration of the heating season. The Belgian gas industry currently uses $16.5^{\circ} \mathrm{C} / 16.5^{\circ} \mathrm{C}$ as double base temperature as this was found to correlate better with the gas consumption [20]. The base temperature at which a good correlation is found highly depends on the region, building type and usage and thermal characteristics $[15,22]$.This explains the diversity in base temperatures used.

To consider the effect of internal and solar gains, thermal inertia and insulation level, the concepts of equivalent HDD (EHDD) and dynamic equivalent HDD were introduced [10,20,27,28]. Two concepts of EHDD are available. In a first concept, used by the gas industry [20] (referred to as normal equivalent HDD), the mean daily external temperature is adapted and defined as follows:

$$
T_{e}=0.6 \cdot T_{m}+0.3 \cdot T_{m-1}+0.1 \cdot T_{m-2}[20]
$$

With $T_{e}=$ adapted daily temperature, $T_{m}=$ daily mean temperature; $T_{m-1}=$ daily mean temperature of the previous day and $\mathrm{T}_{\mathrm{m}-2}=$ daily mean temperature of two days before.

This modification was introduced in 1993 as it was found that the correlation with the actual gas consumption improved when considering an external temperature that includes this weighting. 

days for each day for which the temperature of no more heating (no heating is needed above this temperature due to internal gains by people, lighting, appliances etc.) is higher than the temperature without heating"[27]. The temperature without heating is the average outdoor temperature plus an increase due to the solar gains (depending on e.g. the window characteristics, shading by objects and insulation level). The second concept of EHDD allows a refinement of the calculation of the heating demand in the early design phase by proposing a static value for the EHDD, e.g. $1200^{\circ} \mathrm{d}$ as determined in the research of Allacker [28] for well insulated residential buildings. In addition to the static calculation approach of solar gains (based on the Belgian Energy Performance standard), internal and external gains can be calculated with more or less detail and the resulting reduction of the degree days based on the characteristics of the building. The research of Trigaux et al. [10,29] used a semiit cannot be used to describe the evolution of HDD for buildings in general, which is the aim of this paper.

\subsubsection{Evolutions and trends for HDD in Belgium}

The Belgian gas industry currently uses 2301 normal EHDD defined for a double base temperature of $16.5^{\circ} \mathrm{C} / 16.5^{\circ} \mathrm{C}$ (since $1^{\text {st }}$ of September 2016). Normal refers to the fact that it is the average of EHDD over a certain period. In this case they are calculated based on weather data between 1986-2015 for Uccle with a weighted mean temperature according to equation (1) [20]. Between 2011 and 2015, the reference value was 2363 normal EHDD defined for 1981-2010 [20,30]. The Agri4Cast dataset gives an overview of the monthly HDD across Europe based on temperature observations from weather stations [31], considering daily mean temperatures and a double base temperature of $15^{\circ} \mathrm{C} / 18^{\circ} \mathrm{C}$. There are on average $2748 \mathrm{HDD}$ for Belgium over the period 1986-2015. Over this period, the province of Luxembourg (situated in the Southeast of Belgium) has the highest mean number of HDD, i.e. 3092, while East-Flanders (situated in the North/Northwest of Belgium) has the lowest, i.e. 2517 HDD. Regional differences are noticeable over the different provinces and even over different districts within one province. Local differences (e.g. urban heat island effect) within a district are however not visible on this spatial resolution. 
Despite different base temperatures and calculation methods, a clear decrease of the number of HDD is noticed over the past decades. The Agri4Cast dataset $\left(15^{\circ} \mathrm{C} / 18^{\circ} \mathrm{C}\right)$ [31] shows an average reduction of $12 \mathrm{HDD}$ per year over the period 1974-2018 for Belgium. Similar trends are found for the different regions and districts. Further, the HDD calculated by the Belgian gas industry [20] for Uccle $\left(16.5^{\circ} \mathrm{C} / 16.5^{\circ} \mathrm{C}\right)$ for the period $1961-2018$ show a reduction of 9 EHDD per year. The defined normal EHDD by the Belgian gas industry evolved from 2489 in 1996 (calculated between 1966-1995) to 2301 in 2016 (calculated between 1986-2015) or a reduction of 7.5\%. Last, the HDD calculated for the weather station of Beerse $\left(18^{\circ} \mathrm{C}\right)$ show an average decrease of 5 HDD per year over the period 2005-2018 [32]. The evolution of the HDD from 1961 onwards based on these various sources is provided in Figure 1. The research of Spinoni et al. [13] shows a reduction between 6 HDD per year for the period 1981-2010 for the region of France, Belgium and the Netherlands for a base temperature of $15.5^{\circ} \mathrm{C}$.

\section{Evolution Heating Degree Days}

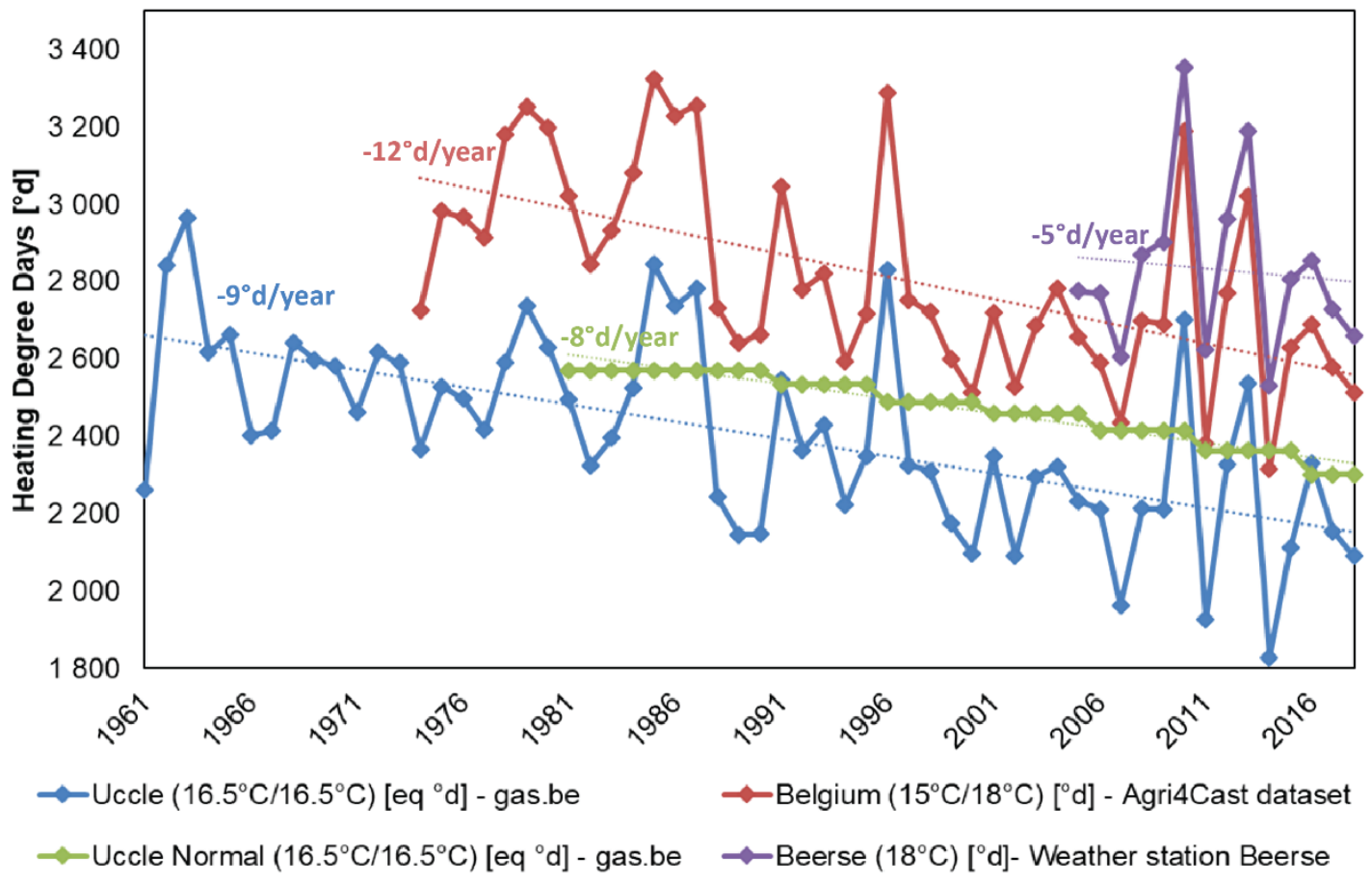

Figure 1: Overview evolution of differently defined HDD according to various data sources (based on [20,31,32])

\subsection{Cooling Degree Days: metric for cooling need}

The definition of the CDD is similar to the one of the HDD accumulating the difference from a base temperature (in this case when the base temperature is exceeded). Also, for the CDD, the hourly time basis is preferred to calculate the number of CDD. 


\subsubsection{Overview CDD methods and evolutions in Belgium}

In contrast to the long-term use of HDD, CDD are not commonly used in Belgium as heating is required to obtain a good thermal comfort in the Belgian climate while cooling can often still be avoided by a good design. Recently, different international sources are however publishing CDD for the Belgian context $[16,31,32]$. Typically, daily mean temperatures are used. Like the HDD, a single or double base temperature are used to calculate the number of CDD. The Agri4Cast dataset uses the double base temperature of $24^{\circ} \mathrm{C} / 21^{\circ} \mathrm{C}$ [31], while the weather station of Beerse uses $18^{\circ} \mathrm{C}$ as base temperature [32] and the research of Spinoni et al. $22^{\circ} \mathrm{C}$ [16]. Several values for the base temperatures can be found in literature, ranging from 10 to $27 \cdot 5^{\circ} \mathrm{C}[12,16,21,23-25]$. The research of Conradie [12] uses a base temperature of $18^{\circ} \mathrm{C}$ for South-Africa. The research of Spinoni $[13,16]$ uses a base temperature of $22^{\circ} \mathrm{C}^{\circ} \mathrm{C}$ for Europe, while the International Energy Agency uses a base temperature of $18^{\circ} \mathrm{C}$ for a worldwide estimate [25]. In the research of De Rosa et al. [11] the base temperature is set to $26.7^{\circ} \mathrm{C}$, the internal temperature setpoint for cooling. The research of Chiesa [23] uses a base temperature of $26^{\circ} \mathrm{C}$ for Italy. The research of Papakostas and Kyriakis [24] refers to $18.3^{\circ} \mathrm{C}$ as base temperature, but stresses that this leads to an overestimation of CDD. Consequently, in this study, CDD are calculated with base temperature varying from 20 to $27.5^{\circ} \mathrm{C}$ per $0.5^{\circ} \mathrm{C}$ for Athens, Greece. The ASHRAE book of fundamentals refers to $10^{\circ} \mathrm{C}$ and $18.3^{\circ} \mathrm{C}$ as most commonly used base temperatures [26].

\subsubsection{Evolutions and trends for CDD in Belgium}

Firstly, the Agri4Cast dataset provides an overview of the monthly CDD across Europe based on daily mean temperatures from weather stations between 1974 and 2018 [27] for a double base temperature of $24^{\circ} \mathrm{C} / 21^{\circ} \mathrm{C}$. CDD are available for the country, the different provinces and districts. For the period 1974-2018, there are on average 13 CDD with a standard deviation of 13 CDD. A long-term increase of 0.27 CDD per year is noticed with regional variations. Secondly, the weather station of Beerse shows an average of $107 \mathrm{CDD}$ for a $18^{\circ} \mathrm{C}$ base temperature between 2005 and 2018 with an increase of 2.6 CDD per year [32]. The difference with the Agri4Cast dataset is caused by a different base temperature. The evolution of the CDD from 1974 onwards based on these various sources is provided in Figure 2. Lastly, the research of Spinoni et al. [13] shows an increase of 1.4 CDD per year between 1981 and 2010 for France, Belgium and the Netherlands calculated for a base temperature of $22^{\circ} \mathrm{C}$. 


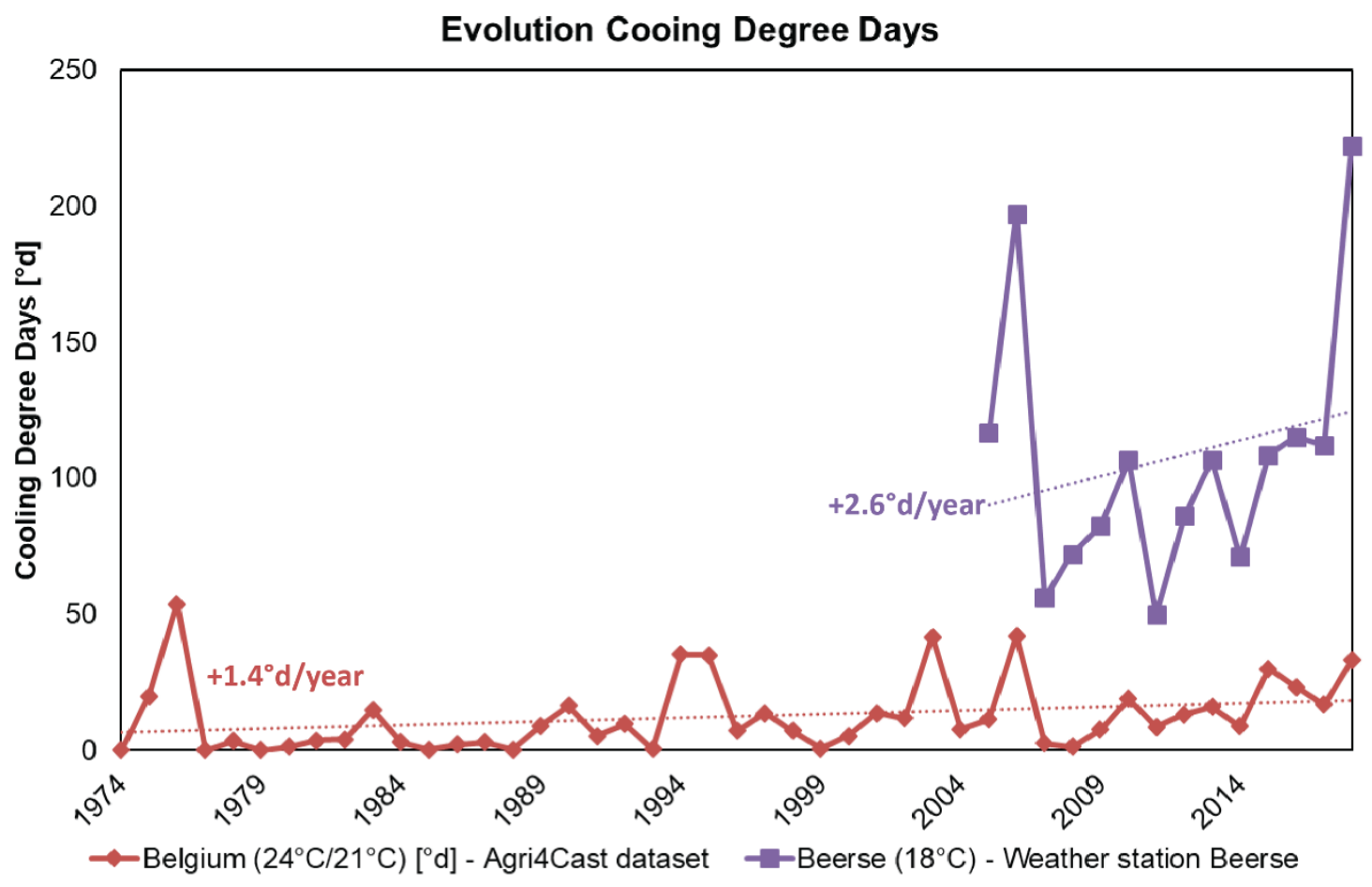

\section{Climate models for future projections of Degree Days}

For the estimates of HDD and CDD in the future considering climate change, climate models can be used. General circulation models (further abbreviated as GCM) provide climate information on the global scale (typically at a resolution of $150-600 \mathrm{~km})[1,33]$. As described in [34] a GCM can be dynamically downscaled to a regional climate model (further abbreviated as a RCM) with a finer grid resolution (typically $10-100 \mathrm{~km}$ ). Climate models incorporate scenarios (e.g. the RCP scenarios described in the introduction) for natural (e.g. solar activity or volcanic eruptions) and anthropogenic (e.g. anthropogenic carbon emissions) forcing [35]. The resulting climate dataset can be used for the calculation of HDD and CDD in future climate conditions.

\subsection{Overview of DD calculated based on climate models for Belgium}

In the research of Spinoni et al. [16] 11 bias-adjusted RCMs with a spatial resolution of $0.11^{\circ}(\sim 12.5 \mathrm{~km})$ are used to estimate the change in HDD by the end of the $21^{\text {st }}$ century for the RCP 4.5 and RCP 8.5 climate change scenarios. The Climate Change Knowledge Portal of the World Bank (CCKP) uses the Coupled Model Intercomparison Project Phase 5 (CMIP5) multi-model ensemble which provides a framework for coordinated climate change experiments used for the IPCC's fifth assessment report. HDD and CDD are calculated based on 
daily data. Influences of urban morphology are not captured on this spatial resolution and will be further discussed in section 4. Also, with a lower spatial resolution it is not possible to obtain data with a high temporal resolution because of convergence of the model run.

\subsection{Trends for future HDD and CDD in Belgium}

Towards the future, a further decrease of the HDD and further increase of CDD is systematically predicted by various researchers for the different climate change scenarios. Of course, the use of different climate models and the uncertainty related to climate change lead to different weather datasets to calculate the number of DD and explains the different values obtained.

The research of Spinoni et al. [16] based on 11 bias-adjusted RCMs as described in [16,36] shows a further decrease of $3.2 \pm 0.4 \mathrm{HDD} /$ year for the RCP 4.5 climate change scenario and $6 \pm 0.4 \mathrm{HDD} /$ year for the RCP 8.5 scenario for France and the Benelux. A base temperature of $15.5^{\circ} \mathrm{C}$ is used. For the southern part of Belgium (i.e. the Walloon region) the reduction is slightly higher than for the northern part of the country (i.e. the Flemish region). A study by the World Bank Group shows a mean decrease between \pm 50 and \pm 220 HDD by 2080 -2099 in comparison to $1986-2005$ for different climate change scenarios for a base temperature of $18.3^{\circ} \mathrm{C}$ [17].

For the CDD, the research of Spinoni et al. [16] reports an increase of $0.8 \pm 0.1 \mathrm{CDD} /$ year for the RCP 4.5 scenario and $2.0 \pm 0.2 \mathrm{CDD} /$ year for the RCP8.5 scenario for a base temperature of $22^{\circ} \mathrm{C}$ by the end of the $21^{\text {st }}$ century. The CCKP reports an increase between 169 and 669 CDD for 2080-2099 in comparison to 1986-2005 for a base temperature of $18.3^{\circ} \mathrm{C}[18]$.

\section{Convection-permitting climate models for Degree Day calculation}

In Belgium, DD are mostly calculated based on observational data from weather stations as was mentioned before. In some cases, e.g. the Agri4Cast dataset, these are interpolated to obtain averages over certain regions. The results from the different weather stations were interpolated and presented on the level of the country, the provinces and different districts shown in Figure 3a and b. It can be noticed that averaging over a bigger area results in a loss of detail in the results. While weather stations only provide specific information for several locations, climate models give continuous information across a region. The climate models used in the research 
of Spinoni et al. [16] and CCKP reports [18] typically have a spatial resolution around $10 \mathrm{~km}$ and a daily temporal resolution. As mentioned before, a higher temporal resolution for this spatial resolution is not possible because of convergence reasons of these climate models. However, an hourly resolution is preferred to calculate DD as the use of daily mean temperatures risks to miss several hours when the temperature exceeds the base temperature. In addition, in a region of 10 by $10 \mathrm{~km}$, differences can be noted due to the territorial settings such as the urban heat island effect [37,38] or the proximity of mountains [39].
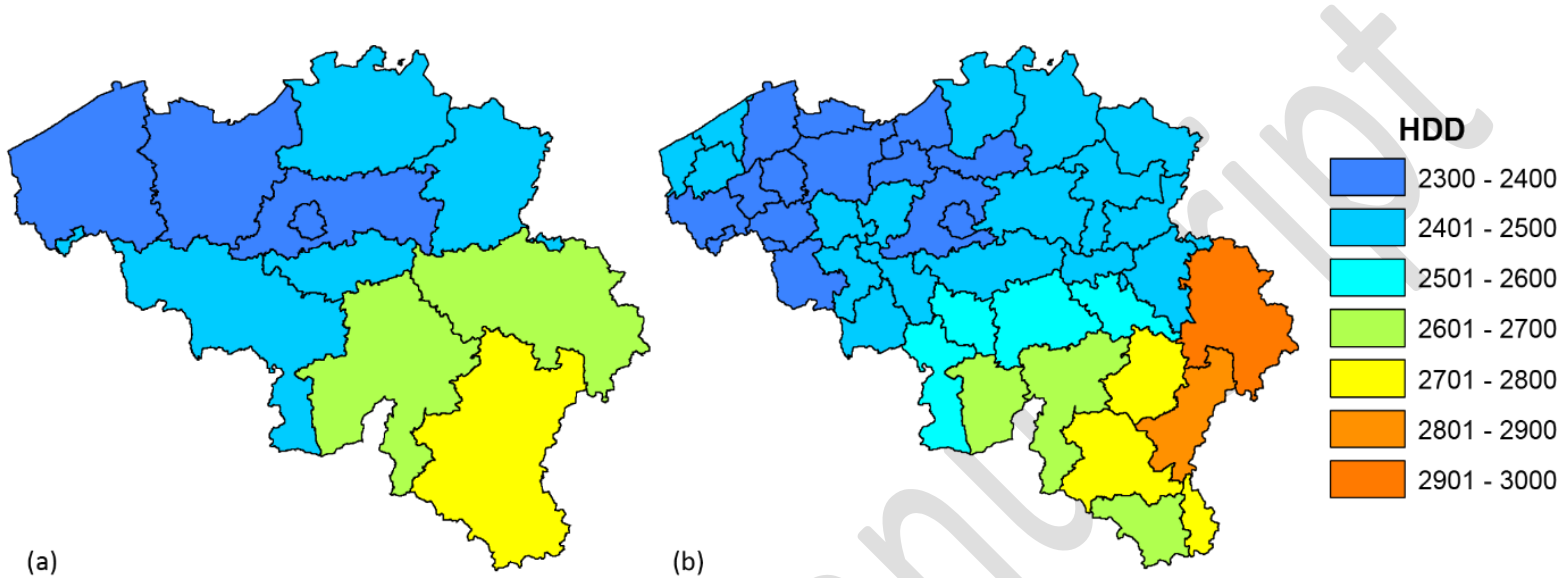

Figure 3: HDD mapped on province (a) and district (b) level based on Agri4Cast dataset for 2018 [31]

A convection-permitting model (further abbreviated as CPM) is a regional climate model at convectionpermitting level (spatial resolution $<4 \mathrm{~km}$ ) that does represent these spatial variations. These models moreover have other advantages, especially in the improved representation of extreme precipitation [40-42]. Advantages making them favourable for building energy performance assessments are: (1) better resolved daily cycle due to explicit resolving of processes instead of using parametrisations [41,43]; (2) better resolved land use and orography due to the high spatial resolution $(<4 \mathrm{~km})[40,42-45]$; (3) better resolved cloud process resulting in a better representation of the incoming shortwave radiation [44]; and (4) explicit representation of the urban heat island effect $[37,38,42]$. The latter is crucial for the analysis of heat stress in buildings located in urban areas $[37,38]$. The high spatial resolution also allows a high temporal resolution. Consequently, a more accurate estimate of DD for a specific location can be obtained avoiding the additional need for correction factors or an over- or underestimation of the DD caused by the use of daily mean temperatures $[9,12,15]$.

\subsection{Convection-permitting climate model for Belgium}

For Belgium, a CPM (2.8 km resolution) is available for the recent past (1975-2005) and future (2069-2099) [45]. The CPM has a spatial resolution of $2.8 \mathrm{~km}$ which is high enough to resolve deep convection explicitly and only 
a parametrisation for shallow convection is needed. In this case, the COSMO-CLM is used as RCM. This model is developed by the German weather service for numerical weather prediction and later adapted for climate simulations $[38,46]$. The CPM for the Belgian domain is obtained by dynamically downscaling the Belgian domain using a two-step nesting strategy [34,46]. Firstly, the $12 \mathrm{~km}$ resolution RCM simulation for the European domain was nested in the EC-Earth domain. Secondly, the $2.8 \mathrm{~km}$ resolution simulation for the Belgian domain was nested in the $12 \mathrm{~km}$ resolution European domain. EC-Earth is a general circulation model (GCM) developed by 27 research institutions across Europe and is part of the CMIP5 multi model ensemble [46]. For each nesting step, the lateral boundary conditions of the EC-Earth driven COSMO-CLM simulation are used resulting from the COordinated Regional climate Downscaling EXperiment (CORDEX) for Europe.

To incorporate the local characteristics and the three-dimensional structure of the urban canopy, the COSMOCLM model is extended with the urban land-surface scheme TERRA_URB (v2.0) making use of the SURY (Semiempirical URban canopY) parametrization $[47,48]$. TERRA_URB calculates radiation, heat and moisture fluxes between the urban environment and the atmosphere based on the bulk parameters (e.g. heat conductivity, albedo, aerodynamical roughness length ...). In addition, SURY translates the urban canopy parameters (e.g. building height, roof fraction, albedo, heat conductivity ...) into bulk parameters used in the climate model [47]. The impervious surface area, defined as the sealed area by buildings and other constructions per total area (further abbreviated as ISA) and the altitude (further abbreviated as h) for this CPM are presented in Figure 4 and Figure 5, respectively. The ISA is based on a European dataset of the impervious surface area from the environmental agency. 


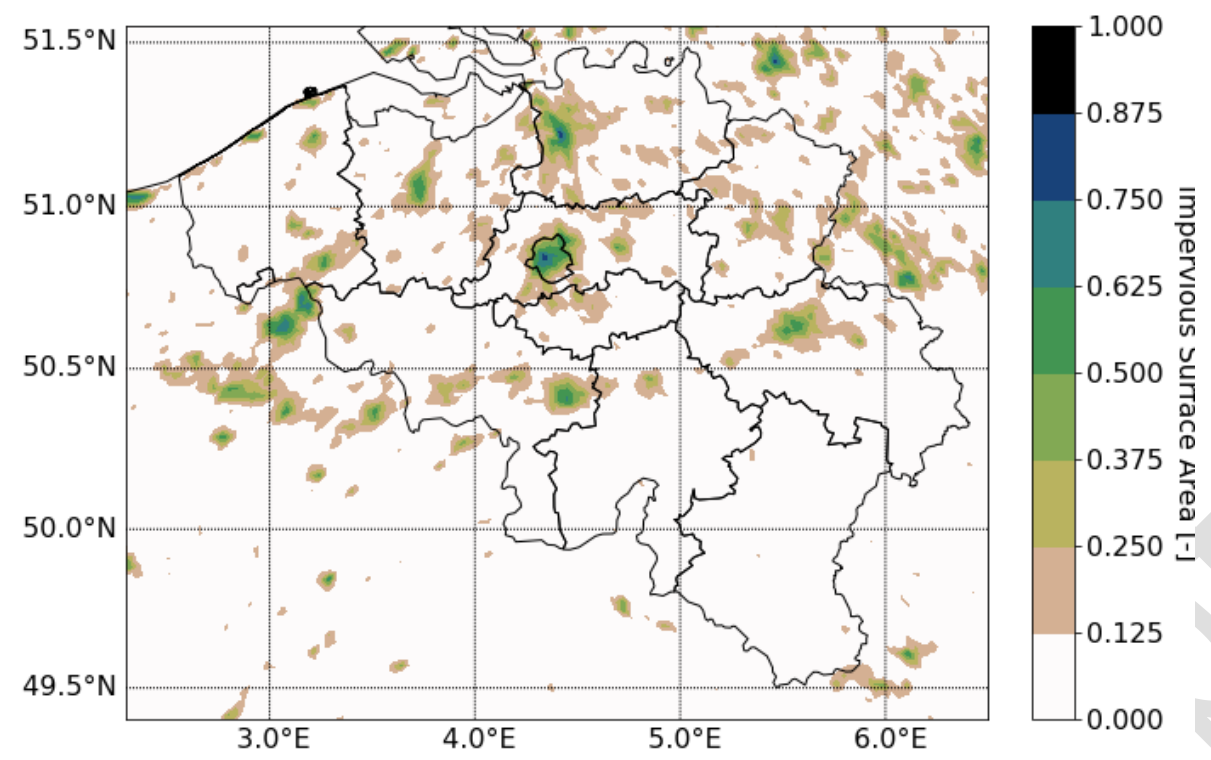

Figure 4: Impervious surface area extracted from convection-permitting climate model data for model domain.

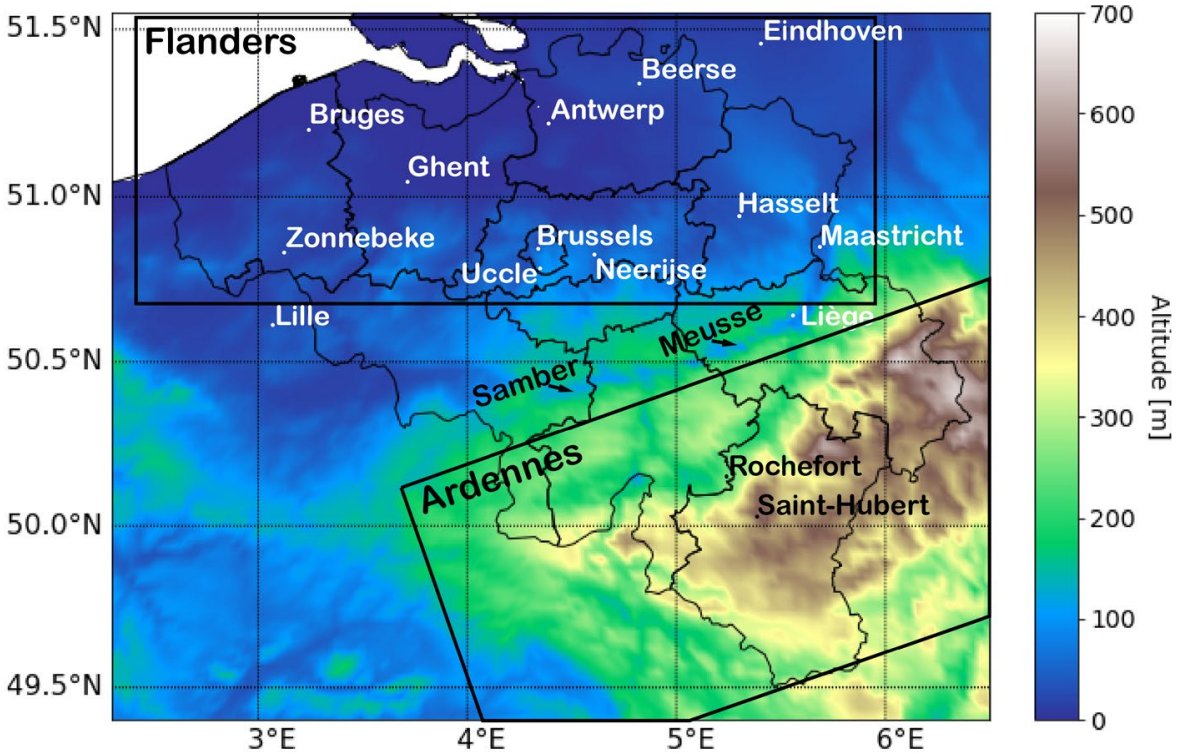

Figure 5: Altitude extracted from convection-permitting climate model data for model domain.

\section{Data and Methodology}

\subsection{Climate model Data}

275 In this paper, the EC-Earth driven CPM for the Belgian domain extended with land-surface scheme TERRA_URB

276 (see section 4.1) is used. The model has a spatial resolution of $2.8 \mathrm{~km}$ and an hourly temporal resolution and is 
available for the recent past (1975-2005) and future (2069-2099) as 30-year datasets. As the first year of the simulation runs is a spin-up and the last year is not complete, these are excluded from the calculation of the HDD and CDD in this paper.

The future climate run uses one of the 16 EC-Earth realisations for the RCP8.5 scenario. As discussed in Vanden Broucke et al. [46], all these realisations have the same model settings, but different initialisation dates resulting in a variability of the climate change signal. The realisation chosen is the EC-Earth member with the most median climate change signal regarding temperature, precipitation and widespread circulation patterns for the RCP8.5 scenario for Belgium $[46,49]$. For the run of the recent past, historical emissions are used for the anthropogenic forcing of the GCM. To increase the model performance, a bias correction is applied on the hourly temperature fields. Details about the bias correction can be found in Text S1 of the supporting information.

\subsection{Heating and Cooling Degree Days}

The number of HDD and CDD are calculated for the recent past (1976-2004) and the future (2070-2098) using the following equations:

$$
\begin{aligned}
H D D & =\frac{\sum_{j=1}^{N}\left(\theta_{b}-\theta_{e}\right)\left(\left(\theta_{b}-\theta_{e}\right)>0\right)}{N} \\
C D D & =\frac{\sum_{j=1}^{N}\left(\theta_{e}-\theta_{b}\right)_{\left(\left(\theta_{e}-\theta_{b}\right)>0\right)}}{N}
\end{aligned}
$$

With:

$$
\begin{aligned}
& \theta_{e}: \text { outdoor hourly temperature }\left[{ }^{\circ} \mathrm{C}\right] \\
& \theta_{b}: \text { base temperature }\left[{ }^{\circ} \mathrm{C}\right]=18^{\circ} \mathrm{C}
\end{aligned}
$$

$\mathrm{N}$ : the hours of the time series

In section 2 it became clear that different base temperatures are used to calculate the number of DD. As the aim of this paper is to characterise the number of HDD and CDD for the Belgian climate independent from the type and usage of a building, $18^{\circ} \mathrm{C}$ is chosen as a base temperature to determine both the number of HDD and CDD. The use of the same temperature moreover avoids an overlap or dead band between the heating and cooling demands [12]. Furthermore, $18^{\circ} \mathrm{C}$ is commonly used as base temperature $[2,11,25,26]$ as discussed in section 2 . The number of HDD and CDD is calculated for each year of the 30-year model run, and the results are presented 
based on a mean, $5^{\text {th }}$ percentile and $95^{\text {th }}$ percentile map over the years of the climate model. The $5^{\text {th }}$ percentile corresponds to the nearly warmest and coldest year for respectively the HDD and CDD (i.e. there are two years which have a lower amount of HDD or CDD). The opposite holds for the $95^{\text {th }}$ percentile corresponding to the almost coldest or warmest year (in case of the HDD or CDD, i.e. there are two years which have a higher amount of HDD or CDD). To investigate the difference in DD obtained by a calculation based on hourly or mean daily temperatures, both are calculated and compared.

\section{Results}

For both the recent past and future run, HDD and CDD maps are presented for the mean, $5^{\text {th }}$ percentile and $95^{\text {th }}$ percentile of the distribution of the 30-year periods, complemented with the delta between both runs. In addition, a table is given with the DD for certain locations and areas with a certain level of urban area fraction or altitude. Belgium is characterised by an urban sprawl throughout the country with cities of different sizes as

Currently, the number of mean HDD for Belgium fluctuate between 2200 and 4600 (Figure 6). The highest values of HDD are reached in the Ardennes, indicated in red on the maps. The Flemish region is in general characterised 
[16] and the World Bank Group [18]. The research of Spinoni et al. [16] estimates absolute reductions between \pm 700 and \pm 1100 HDD between 1981-2010 and 2071-2100 for the RCP8.5 scenario.

The delta maps (lowest row of maps in Figure 6) show a higher absolute reduction in the Ardennes region. The reduction in urban and valley areas is lower than for their surroundings. On average, a reduction of $30 \%$ is estimated with higher relative reductions for the seaside and lower ones for the Ardennes. The warmer years (i.e. the $5^{\text {th }}$ percentile map) have the highest absolute reductions compared to the colder years (i.e. $95^{\text {th }}$ percentile map). In other words, warmer winters will get even warmer in future. Also, for the colder winters, those regions with the highest number of HDD (i.e. the Ardennes and the seaside) are expected to reduce more in absolute terms. The reduction in the inland is lower with an even smaller reduction in urban regions.

Table 1 provides a summary of some specific HDD values for specific locations and average values for the regions
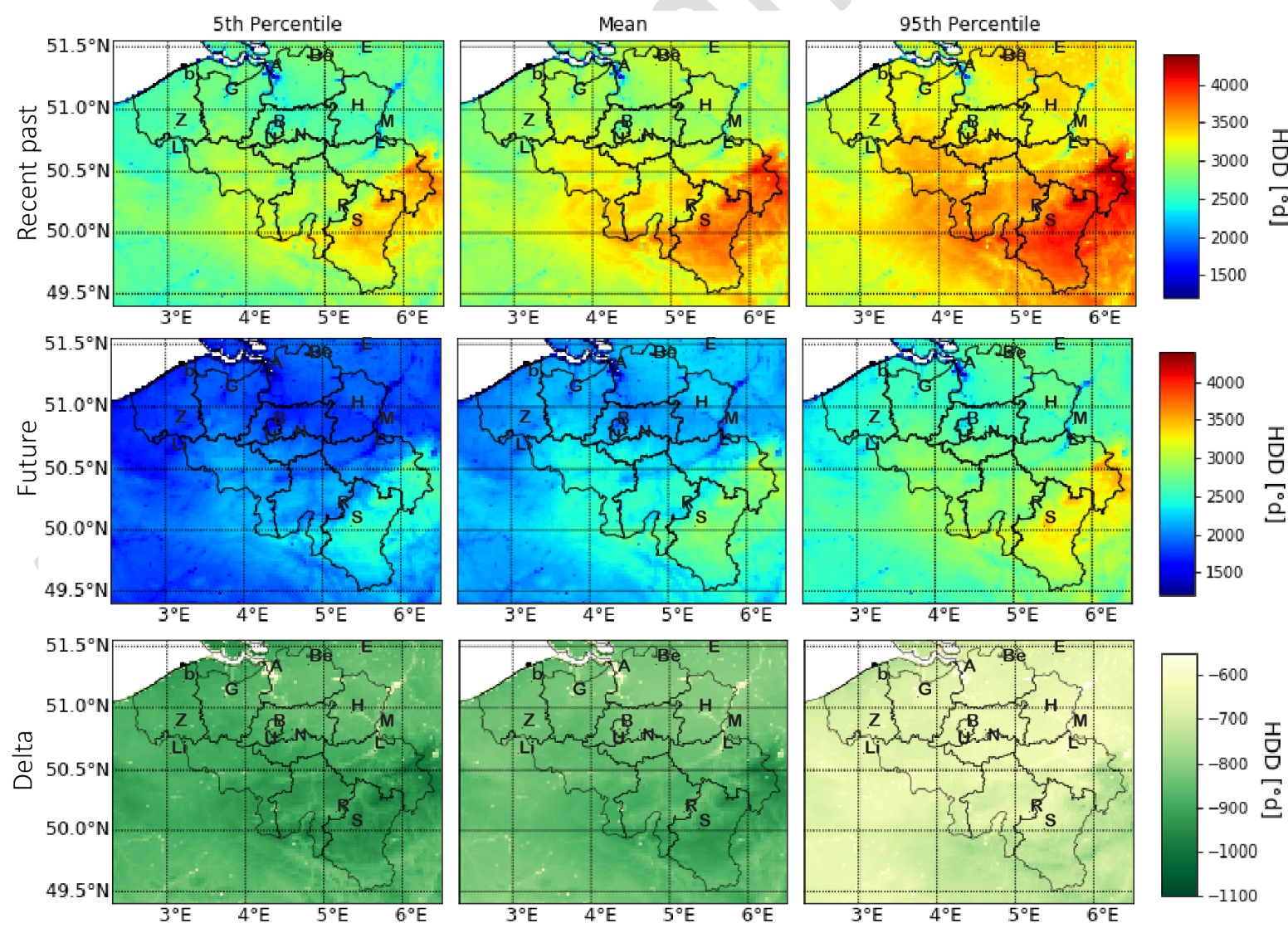


\begin{tabular}{|c|c|c|c|c|c|c|c|c|c|}
\hline & \multicolumn{3}{|c|}{ Mean } & \multicolumn{3}{|c|}{ 5th Percentile } & \multicolumn{3}{|c|}{ 95th Percentile } \\
\hline & $\begin{array}{c}\text { past } \\
\text { 1976-2004 }\end{array}$ & $\begin{array}{c}\text { Future } \\
2070-2098\end{array}$ & $\Delta$ & $\begin{array}{l}\text { past } \\
\text { 1976-2004 }\end{array}$ & $\begin{array}{c}\text { Future } \\
2070-2098\end{array}$ & $\Delta$ & $\begin{array}{c}\text { past } \\
\text { 1976-2004 }\end{array}$ & $\begin{array}{c}\begin{array}{c}\text { Future } \\
2070-2098\end{array}\end{array}$ & $\Delta$ \\
\hline Belgium & 3189 & 2337 & $-27 \%$ & 2907 & 2012 & $-31 \%$ & 3449 & 2775 & $-20 \%$ \\
\hline ISA $>0.75$ & 2649 & 1863 & $-30 \%$ & 2371 & 1551 & $-35 \%$ & 2906 & 2279 & $-22 \%$ \\
\hline ISA $0.25-0.5$ & 2911 & 2090 & $-28 \%$ & 2632 & 1766 & $-33 \%$ & 3170 & 2517 & $-21 \%$ \\
\hline$>250 \mathrm{~m}$ height & 3557 & 2658 & $-25 \%$ & 3261 & 2329 & $-29 \%$ & 3821 & 3116 & $-18 \%$ \\
\hline Brussels & 2855 & 2042 & $-28 \%$ & 2587 & 1727 & $-33 \%$ & 3099 & 2457 & $-21 \%$ \\
\hline $\begin{array}{r}\text { Brussels (city) (ISA } \\
=0.83 ; \mathrm{h}=32 \mathrm{~m} \text { ) }\end{array}$ & 2584 & 1805 & $-30 \%$ & 2305 & 1501 & $-35 \%$ & 2829 & 2215 & $-22 \%$ \\
\hline Flanders & 2975 & 2149 & $-28 \%$ & 2699 & 1830 & $-32 \%$ & 3238 & 2571 & $-21 \%$ \\
\hline $\begin{array}{r}\text { Antwerp (ISA }=0.85 ; \\
h=3 \mathrm{~m})\end{array}$ & 2626 & 1845 & $-30 \%$ & 2343 & 1526 & $-35 \%$ & 2898 & 2266 & $-22 \%$ \\
\hline $\begin{array}{r}\text { Bruges (ISA =0.39; } \\
\mathrm{h}=3.5 \mathrm{~m})\end{array}$ & 2778 & 1944 & $-30 \%$ & 2546 & 1649 & $-35 \%$ & 3019 & 2312 & $-23 \%$ \\
\hline $\begin{array}{r}\text { Ghent (ISA }=0.47 ; \\
\mathrm{h}=5.2 \mathrm{~m})\end{array}$ & 2847 & 2036 & $-28 \%$ & 2607 & 1735 & $-33 \%$ & 3089 & 2431 & $-21 \%$ \\
\hline $\begin{array}{r}\text { Hasselt (ISA }=0.40 \\
\mathrm{~h}=43.1 \mathrm{~m})\end{array}$ & 2862 & 2059 & $-28 \%$ & 2543 & 1720 & $-32 \%$ & 3168 & 2513 & $-21 \%$ \\
\hline $\begin{array}{r}\text { Zonnebeke (ISA =0.07; } \\
\mathrm{h}=44.3 \mathrm{~m})\end{array}$ & 2948 & 2695 & $-29 \%$ & 2695 & 1813 & $-33 \%$ & 3186 & 2502 & $-21 \%$ \\
\hline $\begin{array}{r}\text { Neerijse (ISA }=0.03 ; \\
\mathrm{h}=51.8 \mathrm{~m})\end{array}$ & 2985 & 2160 & $-28 \%$ & 2698 & 1846 & $-32 \%$ & 3244 & 2591 & $-20 \%$ \\
\hline $\begin{array}{r}\text { Beerse (ISA=0.11; } \\
\mathrm{h}=24.7 \mathrm{~m})\end{array}$ & 3066 & 2241 & $-27 \%$ & 2766 & 1911 & $-31 \%$ & 3340 & 2677 & $-20 \%$ \\
\hline Walloon & 3364 & 2491 & $-26 \%$ & 3076 & 2161 & $-30 \%$ & 3622 & 2942 & $-19 \%$ \\
\hline $\begin{array}{r}\text { Liège (ISA=0.50; } \\
h=76.6 \mathrm{~m})\end{array}$ & 2678 & 1904 & $-29 \%$ & 2364 & 1571 & $-34 \%$ & 2973 & 2367 & $-20 \%$ \\
\hline $\begin{array}{r}\text { Rochefort (ISA }=0.05 ; \\
h=236.1 \mathrm{~m})\end{array}$ & 3244 & 2391 & $-26 \%$ & 2947 & 2047 & $-31 \%$ & 3513 & 2855 & $-19 \%$ \\
\hline $\begin{array}{r}\text { Saint-Hubert (ISA =0.06; } \\
h=497.3 \mathrm{~m})\end{array}$ & 3817 & 2887 & $-24 \%$ & 3527 & 2571 & $-27 \%$ & 4055 & 3345 & $-18 \%$ \\
\hline
\end{tabular}

339 Table 1: Overview of HDD for regions and cities in Belgium.

\subsection{Cooling Degree Days}

341 Similar as for the HDD, Figure 7 shows the mean, $5^{\text {th }}$ percentile and $95^{\text {th }}$ percentile maps for the recent past and future run and the delta between both for the CDD. Table 2 shows some specific CDD values for specific locations and average values for the regions (i.e. Belgium, Flanders, Brussels and Walloon region). show a more uniform number of CDD for the whole country, there is some heterogeneity in the mean map and even more in the warmer years (i.e. the $95^{\text {th }}$ percentile map), though still characterised by a low total number of CDD. The effect of urban regions resulting in a higher number of CDD is visible in the mean map, but this 
pattern is even more pronounced for the warmer years (i.e. the $95^{\text {th }}$ percentile map). The $95^{\text {th }}$ percentile map furthermore reveals less CDDs at the seaside and in the Walloon region, more specifically in the Ardennes with exception of the river valleys of the Meuse, Lesse and Sambre. For Uccle a mean value of 121 CDD is obtained, which is higher than the value obtained from literature (see section 2.2.2) due to a different base temperature. Nevertheless, it is in line with the average CDD for Beerse (i.e. 108 CDD) where the same base temperature is used.

The future CDD maps reveal a significant increase in the number of CDD. While in the CDD map of the recent past, the biggest cities of Belgium (e.g. Antwerp, Brussels, Liège ...) are visible, also medium-sized cities (e.g. Hasselt or Kortrijk) become visible for the future run. For the future run, the Northeast of Belgium is characterised by a higher number of CDD than the Northwest or Southern part. Further, the influence of valleys is already visible for the colder years (i.e. the $5^{\text {th }}$ percentile map) of the future run. At the seaside an additional area with a lower amount of CDD appears on the maps for the future run. For Uccle, a mean value of 372 CDD is noticed, which is three times the number for the recent past or an increase of $2.6 \mathrm{CDD} /$ year, which is slightly higher than the result of the research of Spinoni [16] (2.0 \pm 0.2 CDD/year for the RCP 8.5 scenario). The research of Spinoni et al. [16] estimates an increase between \pm 100 and \pm 200 CDD between 1981-2010 and 2071-2100 for the RCP8.5 scenario. This research estimates an increase of \pm 150 to \pm 300 CDD. The use of hourly temperature data was found to lead to higher values for both HDD and CDD.

The delta maps (lowest row of maps in Figure 7) show a bigger absolute increase in cities, the centrum and 

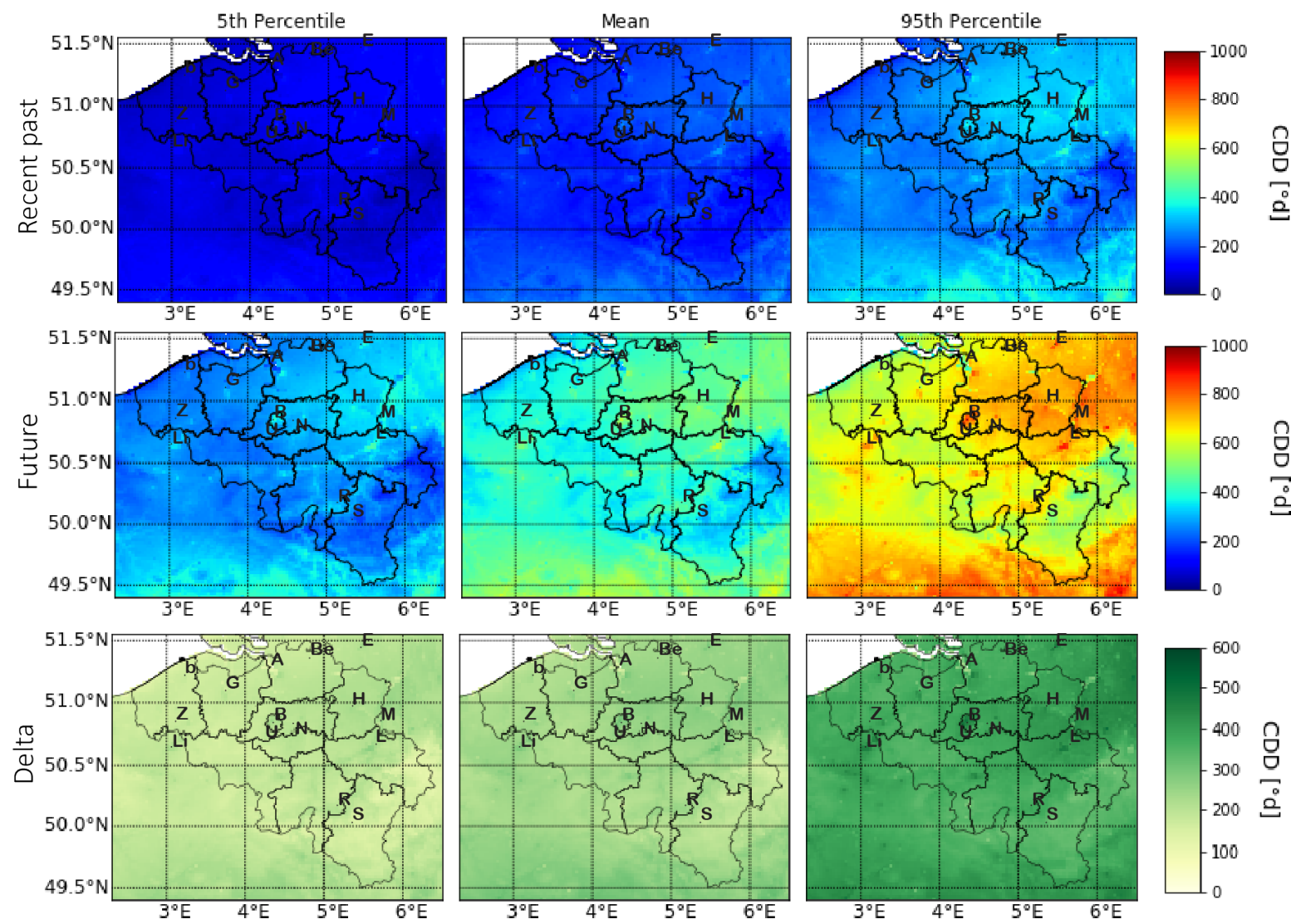

Figure 7: Cooling degree days for Belgian domain for a base temperature of $18^{\circ} \mathrm{C}$ for: a) the recent past; b) future and c)

delta $=$ future minus recent-past results. ( $b=$ Bruges, $Z=$ Zonnebeke, $L i=L i l l e, G=G$ hent, $B=$ Brussels, $U=U c c l e, A=$ Antwerp,

$N=$ Neerijse, $B e=$ Beerse, $E=$ Eindhoven, $R=$ Rochefort, $S=$ Saint - Hubert, $H=$ Hasselt, $M=$ Maastricht, $L=$ Liège)

\begin{tabular}{|c|c|c|c|c|c|c|c|c|c|}
\hline & \multirow{2}{*}{\multicolumn{2}{|c|}{$\begin{array}{c}\text { Mean } \\
\text { Future } \\
2070- \\
2098\end{array}$}} & \multirow[b]{2}{*}{$\Delta$} & \multicolumn{3}{|c|}{ 5th Percentile } & \multicolumn{3}{|c|}{ 95th Percentile } \\
\hline & & & & $\begin{array}{c}\text { Recent } \\
\text { past } \\
1976-2004\end{array}$ & $\begin{array}{c}\text { Future } \\
2070- \\
2098\end{array}$ & $\Delta$ & $\begin{array}{c}\text { Recent } \\
\text { past } \\
1976-2004\end{array}$ & $\begin{array}{c}\text { Future } \\
2070- \\
2098\end{array}$ & $\Delta$ \\
\hline Belgium & 167 & 401 & $141 \%$ & 87 & 271 & $211 \%$ & 268 & 639 & $138 \%$ \\
\hline ISA $>0.75$ & 243 & 547 & $125 \%$ & 141 & 378 & $169 \%$ & 361 & 830 & $130 \%$ \\
\hline ISA 0.25-0.5 & 190 & 448 & $136 \%$ & 103 & 306 & $197 \%$ & 295 & 696 & $136 \%$ \\
\hline$>250 m$ height & 147 & 361 & $146 \%$ & 72 & 241 & $235 \%$ & 242 & 594 & $146 \%$ \\
\hline Brussels & 205 & 478 & $133 \%$ & 112 & 325 & $191 \%$ & 318 & 744 & $134 \%$ \\
\hline $\begin{aligned} \text { Brussels (city) (ISA } & =0.83 ; \\
h & =32 \mathrm{~m})\end{aligned}$ & 257 & 572 & $122 \%$ & 152 & 401 & $164 \%$ & 378 & 865 & $129 \%$ \\
\hline Flanders & 177 & 421 & $138 \%$ & 95 & 284 & $200 \%$ & 281 & 659 & $135 \%$ \\
\hline $\begin{array}{r}\text { Antwerp (ISA }=0.85 ; \\
h=3 \mathrm{~m})\end{array}$ & 246 & 552 & $125 \%$ & 143 & 380 & $166 \%$ & 365 & 832 & $128 \%$ \\
\hline $\begin{array}{r}\text { Bruges (ISA }=0.39 ; \\
\mathrm{h}=3.5 \mathrm{~m})\end{array}$ & 153 & 388 & $154 \%$ & 75 & 248 & $231 \%$ & 227 & 632 & $178 \%$ \\
\hline $\begin{array}{r}\text { Ghent }(\text { ISA }=0.47 \\
h=5.2 \mathrm{~m})\end{array}$ & 183 & 433 & $136 \%$ & 91 & 284 & $213 \%$ & 280 & 689 & $146 \%$ \\
\hline $\begin{array}{r}\text { Hasselt (ISA }=0.40 ; \\
h=43.1 \mathrm{~m})\end{array}$ & 236 & 521 & $121 \%$ & 134 & 368 & $175 \%$ & 359 & 793 & $121 \%$ \\
\hline $\begin{array}{r}\text { Zonnebeke (ISA =0.07; } \\
h=44.3 \mathrm{~m})\end{array}$ & 141 & 366 & $160 \%$ & 73 & 241 & $230 \%$ & 223 & 583 & $162 \%$ \\
\hline
\end{tabular}




\begin{tabular}{|c|c|c|c|c|c|c|c|c|c|}
\hline $\begin{array}{r}\text { Neerijse (ISA =0.03; } \\
\mathrm{h}=51.8 \mathrm{~m})\end{array}$ & 192 & 448 & $134 \%$ & 105 & 305 & $191 \%$ & 312 & 698 & $124 \%$ \\
\hline $\begin{array}{r}\text { Beerse (ISA=0.11; } \\
\mathrm{h}=24.7 \mathrm{~m})\end{array}$ & 188 & 434 & $131 \%$ & 102 & 286 & $181 \%$ & 304 & 671 & $120 \%$ \\
\hline Walloon & 158 & 385 & $143 \%$ & 81 & 260 & $222 \%$ & 257 & 622 & $142 \%$ \\
\hline $\begin{array}{r}\text { Liège (ISA=0.50; } \\
\mathrm{h}=76.6 \mathrm{~m})\end{array}$ & 285 & 606 & $112 \%$ & 175 & 448 & $156 \%$ & 414 & 885 & $114 \%$ \\
\hline $\begin{array}{r}\text { Rochefort (ISA =0.05; } \\
\mathrm{h}=236.1 \mathrm{~m})\end{array}$ & 175 & 413 & $136 \%$ & 93 & 291 & $214 \%$ & 288 & 665 & $131 \%$ \\
\hline $\begin{array}{r}\text { Saint-Hubert (ISA }=0.06 ; \\
\mathrm{h}=497.3 \mathrm{~m})\end{array}$ & 120 & 316 & $164 \%$ & 93 & 199 & $114 \%$ & 210 & 540 & $157 \%$ \\
\hline
\end{tabular}

\subsection{Comparison of HDD and CDD based on low and high spatial and temporal} resolution

\subsubsection{Spatial resolution}

As discussed in section 4.1, a higher spatial resolution is able to capture local effects such as urban heat island effects. This is shown in Figure 8 by comparing the obtained CDD for the recent past at high spatial resolution (Figure 8a) with a lower spatial scale, i.e. mean values calculated based on the available data of weather stations in the respective district from the Agri4cast dataset [31] (Figure 8b). In the high spatial resolution map (Figure 8a), the influence of regional effects such as the distance to the seaside, urbanisation and elevation (as discussed in section 6.2) are clearly visible in the number of CDD, which is clearly only partly captured in the map with mean values at district level (Figure 8b). It should moreover be noted that some of these regional effects that can be seen on the district level map are thanks to the location of the available weather stations (e.g. if for that district the available data originates from weather stations located close to the sea, this will influence the average instead if weather stations are equally spread across the district). The two maps however show that local effects such as urban heat islands and local elevation differences cannot be captured on this lower spatial resolution of districts, while these do exist as shown on the higher spatial resolution map. When zooming in on a district, these local differences become more pronounced. This is illustrated in Figure 9 for the Brussels-Capital region. Figure 9a shows an average of 205 CDD for the recent past, while a maximum value of 257 CDD is reached in the city centre. Table 3 shows that the most urbanised area within the Brussels-Capital municipality has $19 \%$ more CDD than the average number of CDD for the whole Brussels Region. On the other hand, a municipality as Watermaal-Bosvoorde (Southeast of the region) has on average 174 CDD which is $15 \%$ lower than the regional average. A close link exists between the pattern of CDD for that region and the impervious surface area (shown in Figure 9b). Although this section illustrated the importance of spatial scale for CDD, similar findings are 


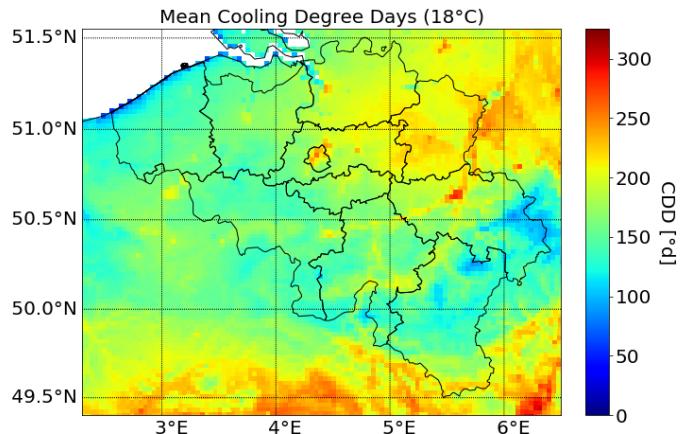

(a)

Figure 8: (a) Mean CDD for Belgian domain; and (b) Average Mean CDD per district for a base temperature of $18^{\circ} \mathrm{C}$ for the

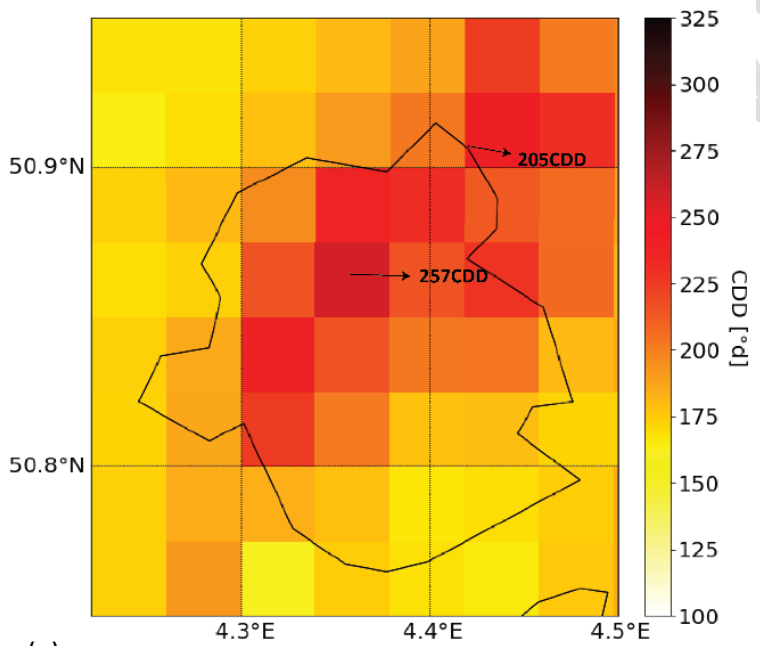

(a)

Figure 9: (a) Mean CDD for the recent past and (b) Impervious Surface Area for the Brussels-Capital region

\begin{tabular}{|c|c|c|c|}
\hline & Mean CCD & $\begin{array}{l}\text { Difference with } \\
\text { regional level }\end{array}$ & $\begin{array}{c}\text { Difference with } \\
\text { municipality level }\end{array}$ \\
\hline Brussels Region & 205 & & \\
\hline Brussels-Capital (municipality) & 218 & $+6 \%$ & \\
\hline ISA $0.25-0.50$ & 209 & $+1 \%$ & $-5 \%$ \\
\hline$I S A>0.75$ & 243 & $+19 \%$ & $+11 \%$ \\
\hline Watermaal-Bosvoorde & 174 & $-15 \%$ & \\
\hline
\end{tabular}




\subsubsection{Temporal resolution}

In the previous sections the HDD and CDD were calculated based on hourly temperature data. Alternatively, one could make the calculations based on daily mean temperature data. Both are compared in this section and discussed to investigate if this leads to large differences. Generally, it is found that calculating DD based on daily mean temperatures lead to a lower amount of DD. Figure 10 shows the difference in calculated DD between the calculations based on hourly and daily mean temperatures for the recent past (Figure 10a) and future(Figure 10b). The difference in absolute values between daily and hourly calculation is the same for both HDD and CDD as the base temperature is the same. Relatively, the difference is higher for the CDD than for the HDD as the total number of CDD is much smaller. For the HDD the relative difference is only $3-4 \%$ of the hourly calculated DD. Table 4 shows the relative differences for the CDD. Towards the future the relative difference decreases as the total number of CDD increases while the importance is higher for the colder years (i.e. $5^{\text {th }}$ percentile) than for the warmer years (i.e. $95^{\text {th }}$ percentile).

\begin{tabular}{l|c|c|c}
\hline & Mean & 5 th Percentile & 95th Percentile \\
\hline Recent past run & $50 \%$ & $75 \%$ & $39 \%$ \\
Future & $24 \%$ & $38 \%$ & $14 \%$
\end{tabular}

Table 4: Difference between CDD calculated based on hourly temperatures and daily mean temperatures for the recent past and future climate run

In the recent past climate run, differences are higher in the Ardennes region which is characterised by colder temperatures and in rural areas where the difference between day and night temperatures is higher.

Towards the future, the difference between the daily and hourly calculation becomes bigger for the Ardennes region, with even more pronounced differences for those areas in the Ardennes with lower altitudes. In these regions with lower altitudes, temperatures are less cold and fluctuate more around the base temperature used for the HDD calculation. Also, in rural areas an increase in the difference towards the future is noticed. For cities, the difference between daily and hourly calculation becomes smaller towards the future, as in general higher temperatures are noticed.

From these results it can be concluded that it is preferred to use hourly temperature values to accurately estimate HDD and CDD, although relatively, the difference for the HDD is very small and could be neglected. 


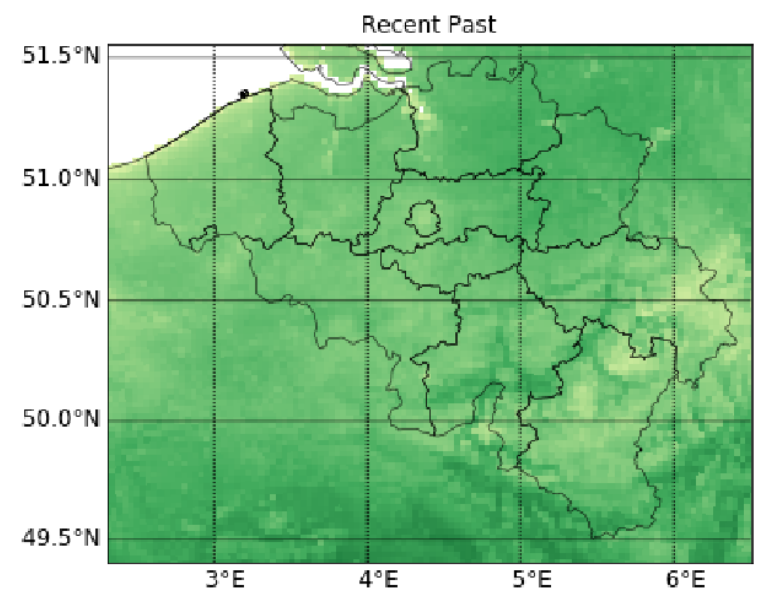

(a)

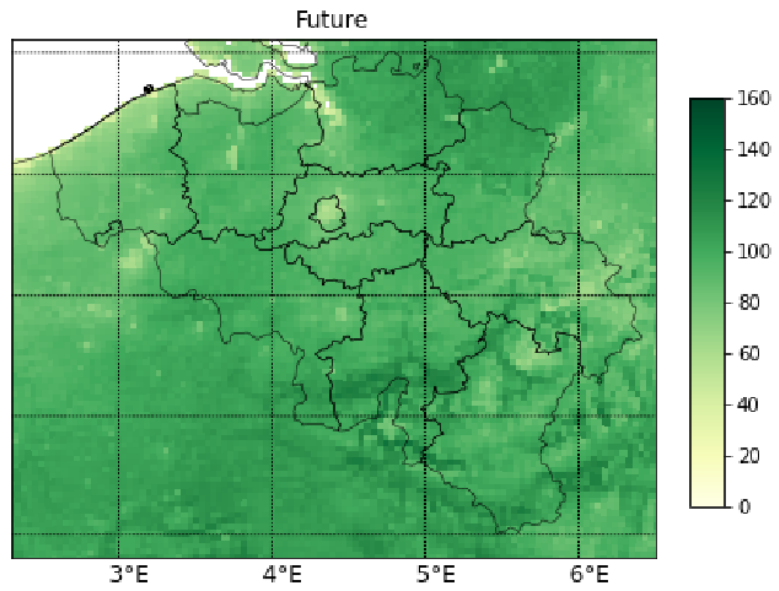

(b)

Figure 10: Difference between mean DD calculated based on hourly temperatures and daily mean temperatures for the (a) recent past and (b) future (positive values mean the calculation based on hourly temperatures lead to higher DD than the calculation based on daily mean temperatures)

\section{Discussion}

As discussed in the state of the art, different temperature settings are possible to calculate the HDD and CDD. As the aim of this paper was to get insights in the changes of HDDs and CDDs without incorporating the effect of building characteristics, $18^{\circ} \mathrm{C}$ was chosen as a base temperature. The use of $18^{\circ} \mathrm{C}$ as base temperature for both HDD and CDD avoids an overlap or dead band between both energy demands. Although the results will differ for other base temperatures, general trends are expected to remain, although further modelling should be done in order to confirm this. In a next step, equivalent HDD and CDD should be calculated which incorporate internal and solar gains from which the building energy use can be estimated. As the number of equivalent HDD or CDD highly depends on the building characteristics, there will not be one fixed number of equivalent HDD or CDD for Belgium.

To obtain climate robust buildings, it is furthermore important to consider the sensitivity of the different climate change scenarios on the results as stated amongst others by Moazami et al. [50] and Nik and Kalagasidis [51]. The latter states a difference up to $30 \%$ for the heating demand and even more for the cooling demand under different climate scenarios. Climate robust buildings only have a limited variability in their performance for different climate change scenarios. The climate model used in this study used one of the 16 EC-Earth realisations for the high-end RCP 8.5 climate change scenario. Consequently, this is only one realisation of a possible future 
climate scenario as mentioned in the introduction. However, for Belgium, the RCM used, COSMO-CLM is only dynamically downscaled till the resolution of $2.8 \mathrm{~km}$ for one realisation due to the computational time needed to obtain a model at this resolution. In future work, a sensitivity analysis should be performed to assess the uncertainty caused by different climate change scenarios as well as for the different existing GCMs driving the RCMs. The latter should be done at least by means of statistic perturbation techniques (considering multiple GCMs) or ideally based on multiple convection-permitting climate models.

It should be noted that for the climate model run used, the urban configuration (i.e. impervious versus permeable surface ratio's) is kept identical for both the current and future run. Of course, this urban configuration and linked anthropogenic fluxes will change towards the future and influence the temperature and thus the number of DD. Wouters et al. [38] show a further increase of the heat stress with urban expansion. Further modelling to incorporate sensitivity of results for urban sprawl and anthropogenic heating is required.

\section{Conclusion}

Degree days are commonly used to estimate the energy use for heating and cooling of buildings in the early design phase. This paper presents the heating and cooling degree days for the recent past and future climate perspective for the Belgian context based on a base temperature of $18^{\circ} \mathrm{C}$. A bias-corrected convectionpermitting climate model ( $2.8 \mathrm{~km}$ resolution) is used to calculate the HDD and CDD based on hourly temperature data for a recent past run (1976-2004) and future run (2070-2098) considering the RCP 8.5 (worst case) climate change scenario. In addition, a comparison is made between (1) a calculation based on hourly and daily mean temperatures and (2) values obtained with a spatial resolution of $2.8 \mathrm{~km}$ compared to district level values.

It was found that the average HDD for Belgium decrease with $27 \%$ ( $852 \mathrm{HDD})$, while the $5^{\text {th }}$ and $95^{\text {th }}$ percentile (representing the respectively the warmer and colder years of the 30 year runs considered) decrease with respectively around 31\% (895 HDD) and 20\% (674 HDD). Higher relative reductions are found for the seaside and urban areas, though the highest absolute reductions are found in the higher regions of Belgium situated in the Ardennes. River valleys are characterised by a lower number of HDD than their surroundings, especially in the Ardennes. Reductions are in line with a previous European study [16]. In contrast to the latter, the use of a convection-permitting climate model in this paper allows to identify differences on a regional level. Further the use of the hourly temporal resolution leads to higher values of CDD and HDD. For CDD it is preferred to use calculation based on hourly values as for the mean CDD differences of $50 \%$ and $24 \%$ were found for respectively 
the recent past and future climate run. For the HDD the differences are limited to some percentages and could be neglected.

For the CDD, the climate context of the recent past is characterised by an overall small number of CDD (i.e. on average 167 CDD for Belgium, 177 CDD for Flanders, 224 CDD for urban areas and 163 CDD for regions $>250 m$ ). Nevertheless, in the $95^{\text {th }}$ percentile (i.e. warmer years of the 30 year period considered), urban areas show a higher number of CDD (i.e. 268 CDD for Belgium, 281 CDD for Flanders, 329 CDD for Urban Areas and 261 CDD for regions $>250 m$ ). Towards the future, a general increase was found up to more than three times the number of CDD today (i.e. on average 401 CDD for Belgium, 271 CDD for Flanders, 511 CDD for Urban Areas and 388 CDD for regions $>250 m$ ). Higher relative increases are found for those areas with currently the lowest amount of CDD, while cities are found to have lower relative increases than their surroundings particularly for the mean and $5^{\text {th }}$ percentile (i.e. colder year of the 30-year period considered). Nevertheless, their absolute increase is higher. Differences are smaller for urban areas as cities are on average warmer and the difference between day and night temperatures is lower due to the urban heat island effect. In comparison to an earlier European study, higher increases are found in this study caused by the use of hourly instead of daily mean temperature data as well as due to the higher spatial resolution considered.

As the effect of building characteristics on the base temperature and therefore HDD and CDD was not considered, this should be a future research step. The methodology of equivalent HDD and CDD could be used for this.

\section{Acknowledgements}

This work was supported by Research Foundation Flanders (FWO) [1S97418N] and is part of the Ph.D. research 'Towards future-proof buildings in Flanders: Climate and Life Cycle modelling for resilient office buildings'. The climate model data used is the result of the CORDEX.be project funded by the Belgian federal government (Belgian Science Policy Office project BR/143/A2/CORDEX.be) and can be requested through the CORDEX.be project website (http://www.euro-cordex.be). Computational resources for these integrations were provided by the VSC (Flemish Supercomputer Centre), funded by the Research Foundation - Flanders (FWO) and the Flemish Government - department EWI. The hourly observational data were provided by RMI (Belgian Royal Meteorological Institute). This dataset is available at this institution upon request. 
500

501

502

503

504

505

506

507

508

509

510

\section{References}

[1] IPCC, Climate Change 2013: The Physical Science Basis. Contribution of Working Group I to the Fifth Assessment Report of the Intergovernmental Panel on Climate Change, CUP, Cambridge, United Kingdom and New York, USA, 2013. doi:10.1017/СBO9781107415324.

[2] M. Isaac, D.P. van Vuuren, Modeling global residential sector energy demand for heating and air conditioning in the context of climate change, Energy Policy. 37 (2009) 507-521. doi:10.1016/j.enpol.2008.09.051.

[3] R.S. Kovats, R. Valentini, L.M. Bouwer, E. Georgopoulou, D. Jacob, E. Martin, M. Rounsevell, J.-F. Soussana, Europe, in: V.R. Barros, and L.L.W. C.B. FieldBarros, V.R., C.B. Field, D.J. Dokken, M.D. Mastrandrea, K.J. Mach, T.E. Bilir, M. Chatterjee, K.L. Ebi, Y.O. Estrada, R.C. Genova, B. Girma, E.S. Kissel, A.N. Levy, S. MacCracken, P.R. Mastrandrea, and L.L. White, D.J. Dokken, M.D (Eds.), Clim. Chang. 2014 Impacts, Adapt. Vulnerability. Part B Reg. Asp. Contrib. Work. Ggr. Il to Fifth Assess. Rep. Intergov. Panel Clim. Chang., Cambridge University Press, Cambridge, United Kingdom and New York, NY, USA, 2014: pp. 1267-1326. doi:10.1007/s13398-014-0173-7.2.

[4] D. Ramon, K. Allacker, Integrating climate change in life cycle assessment of buildings: Literature review, IOP Conf. Ser. Earth Environ. Sci. 323 (2019). doi:10.1088/1755-1315/323/1/012064.

[5] L. Bragança, S.M. Vieira, J.B. Andrade, Early stage design decisions: The way to achieve sustainable buildings at lower costs, Sci. World J. 2014 (2014). doi:10.1155/2014/365364.

[6] S. Attia, E. Gratia, A. De Herde, J.L.M. Hensen, Simulation-based decision support tool for early stages of zero-energy building design, Energy Build. (2012). doi:10.1016/j.enbuild.2012.01.028.

[7] C. Ratti, N. Baker, K. Steemers, Energy consumption and urban texture, Energy Build. (2005). doi:10.1016/j.enbuild.2004.10.010.

[8] E.P.B.D. Recast, Directive 2010/31/EU of the European Parliament and of the Council of 19 May 2010 on the energy performance of buildings (recast)., Off. J. Eur. Union. 06 (2010) 13-35. 
[10] D. Trigaux, B. Oosterbosch, F. De Troyer, K. Allacker, A design tool to assess the heating energy demand

[11] M. De Rosa, V. Bianco, F. Scarpa, L.A. Tagliafico, Heating and cooling building energy demand evaluation; and the associated financial and environmental impact in neighbourhoods, Energy Build. 152 (2017) 516-523. doi:10.1016/j.enbuild.2017.07.057. A simplified model and a modified degree days approach, Appl. Energy. 128 (2014) 217-229. doi:10.1016/j.apenergy.2014.04.067.

[12] D. Conradie, T. van Reenen, S. Bole, Degree-day building energy reference map for South Africa, Build. Res. Inf. 46 (2018) 191-206. doi:10.1080/09613218.2016.1252619.

[13] J. Spinoni, J. Vogt, P. Barbosa, European degree-day climatologies and trends for the period 1951-2011, Int. J. Climatol. 35 (2015) 25-36. doi:10.1002/joc.3959.

[14] ISO, EN ISO 15927-6: 2007 Hygrothermal performance of buildings - Calculation and presentation of climatic data - Part 6: Accumulated temperature differences (degree-days), (2007).

[15] M. Mourshed, Relationship between annual mean temperature and degree-days, Energy Build. 54 (2012) 418-425. doi:10.1016/j.enbuild.2012.07.024.

[16] J. Spinoni, J. V. Vogt, P. Barbosa, A. Dosio, N. McCormick, A. Bigano, H.M. Füssel, Changes of heating and cooling degree-days in Europe from 1981 to 2100, Int. J. Climatol. (2018). doi:10.1002/joc.5362.

[17] World Bank Group, World Bank Climate Change Knowledge Portal, (2019). https://climateknowledgeportal.worldbank.org/about (accessed August 20, 2019).

[18] METADATA OF THE CLIMATE CHANGE KNOWLEDGE PORTAL, 2019. https://climateknowledgeportal.worldbank.org/themes/custom/wb_cckp/resources/data/CCKP_Meta data_Description_2018.pdf (accessed August 18, 2019).

[19] Thomas Boermans (Ecofys Germany); Carsten Petersdorff (Ecofys Germany), U-VALUES FOR BETTER ENERGY PERFORMANCE OF BUILDINGS Report established by ECOFYS for EURIMA, (2007). 
https://www.eurima.org/uploads/ModuleXtender/Publications/13/EURIMA-ECOFYS_VII_report_p1651.pdf (accessed August 8, 2019).

[20] gas.be, Graaddagen - Gas, (n.d.). https://www.gas.be/nl/graaddagen (accessed August 13, 2019).

[21] M. De Rosa, V. Bianco, F. Scarpa, L.A. Tagliafico, Historical trends and current state of heating and cooling degree days in Italy, Energy Convers. Manag. (2015). doi:10.1016/j.enconman.2014.11.022.

[22] Q. Meng, M. Mourshed, Degree-day based non-domestic building energy analytics and modelling should use building and type specific base temperatures, Energy Build. 155 (2017) 260-268. doi:10.1016/j.enbuild.2017.09.034.

[23] G. Chiesa, M. Grosso, The influence of different hourly typical meteorological years on dynamic simulation of buildings, in: Energy Procedia, 2015. doi:10.1016/j.egypro.2015.11.280.

[24] K. Papakostas, N. Kyriakis, Heating and cooling degree-hours for Athens and Thessaloniki, Greece, Renew. Energy. (2005). doi:10.1016/j.renene.2004.12.002.

[25] International Energy Agency, The Future of Cooling. Opportunities for energy-efficient air conditioning, OECD, 2018. doi:10.1787/9789264301993-en

[26] ASHRAE, ASHRAE Handbook 2013 Fundamentals, Www.Ansi.Org Am. Soc. Heating, Refrig. AirConditioning Eng. Inc. (2013). doi:10.1017/СBO9781107415324.004.

[27] Diensten voor Programmatie van het Wetenschapsbeleid (DPWB), Ontwerp en thermische uitrusting van gebouwen, Deel 1 en 2, Brussels, Belgium, 1984.

[28] K. Allacker, Sustainable building - The development of an evaluation method, KU Leuven, 2010. doi:10.1016/S1471-0846(04)00051-4.

[29] D. Trigaux, K. Allacker, F. de Troyer, A simplified Approach to integrate Energy Calculations in the Life Cycle Assessment of Neighbourhoods, in: R. Rawal, S. Manu, N. Khadpekar (Eds.), Sustain. Habitat Dev. Soc. (30th Int. PLEA Conf., CEPT University Press, Ahmedabad, 2014: pp. 279-286. 
[30] Prospectieve studie betreffende de zekerheid van de aardgasbevoorrading tot 2020, 2016.

[31] Joint Research Center, Monthly Cooling and Heating degrees indexes, (2019). https://agri4cast.jrc.ec.europa.eu/DataPortal/Resource_Files/PDF_Documents/10.pdf (accessed August 16, 2019).

[32] Weerstation - Beerse Graaddagen Overzicht, https://www.weerstationkempen.be/website1/wxdegreesummary.php?r=wxdegreesummary.php (accessed August 18, 2019).

[33] D. Jacob, J. Petersen, B. Eggert, A. Alias, O.B. Christensen, L.M. Bouwer, A. Braun, A. Colette, M. Déqué, G. Georgievski, E. Georgopoulou, A. Gobiet, L. Menut, G. Nikulin, A. Haensler, N. Hempelmann, C. Jones, K. Keuler, S. Kovats, N. Kröner, S. Kotlarski, A. Kriegsmann, E. Martin, E. van Meijgaard, C. Moseley, S. Pfeifer, S. Preuschmann, C. Radermacher, K. Radtke, D. Rechid, M. Rounsevell, P. Samuelsson, S. Somot, J.F. Soussana, C. Teichmann, R. Valentini, R. Vautard, B. Weber, P. Yiou, EURO-CORDEX: New highresolution climate change projections for European impact research, Reg. Environ. Chang. 14 (2014) 563-578. doi:10.1007/s10113-013-0499-2.

[34] E. Brisson, M. Demuzere, N.P.M. Van Lipzig, Modelling strategies for performing convection-permitting climate simulations, Meteorol. Zeitschrift. 25 (2016) 149-163. doi:10.1127/metz/2015/0598.

[35] S. Vanden Broucke, The added value of CONVECTION-PERMITTING REGIONAL CLIMATE MODELING. FOR LAND-USE CHANGE IMPACT INDUCED CLIMATE CHANGE, KU Leuven, 2017.

[36] A. Dosio, Projections of climate change indices of temperature and precipitation from an ensemble of bias-adjusted high-resolution EURO-CORDEX regional climate models, J. Geophys. Res. 121 (2016) 54885511. doi:10.1002/2015JD024411.

[37] H. Wouters, K. De Ridder, M. Demuzere, D. Lauwaet, N.P.M. Van Lipzig, The diurnal evolution of the urban heat island of Paris: A model-based case study during Summer 2006, Atmos. Chem. Phys. 13 (2013) 8525-8541. doi:10.5194/acp-13-8525-2013.

[38] H. Wouters, K. De Ridder, L. Poelmans, P. Willems, J. Brouwers, P. Hosseinzadehtalaei, H. Tabari, S. 
Vanden Broucke, N.P.M. van Lipzig, M. Demuzere, Heat stress increase under climate change twice as large in cities as in rural areas: A study for a densely populated midlatitude maritime region Supplementary Documents, Geophys. Res. Lett. 44 (2017) 8997-9007. doi:10.1002/2017GL074889.

[39] T. Berger, C. Amann, H. Formayer, A. Korjenic, B. Pospichal, C. Neururer, R. Smutny, Impacts of urban location and climate change upon energy demand of office buildings in Vienna, Austria, Build. Environ. 81 (2014) 258-269. doi:10.1016/j.buildenv.2014.07.007.

[40] E.J. Kendon, N. Ban, N.M. Roberts, H.J. Fowler, M.J. Roberts, S.C. Chan, J.P. Evans, G. Fosser, J.M. Wilkinson, Do Convection-Permitting Regional Climate Models Improve Projections of Future Precipitation Change?, Bull. Am. Meteorol. Soc. 98 (2017) 79-93. doi:10.1175/BAMS-D-15-0004.1.

[41] N. Ban, J. Schmidli, C. Schär, Evaluation of the convection-resolving regional climate modeling approach in decade-long simulations, J. Geophys. Res. (2014). doi:10.1002/2014JD021478.

[42] A.F. Prein, W. Langhans, G. Fosser, A. Ferrone, N. Ban, K. Goergen, M. Keller, M. Tölle, O. Gutjahr, F. Feser, E. Brisson, S. Kollet, J. Schmidli, N.P.M. Van Lipzig, R. Leung, A review on regional convectionpermitting climate modeling: Demonstrations, prospects, and challenges, Rev. Geophys. 53 (2015) 323361. doi:10.1002/2014RG000475.

[43] E. Brisson, K. Van Weverberg, M. Demuzere, A. Devis, S. Saeed, M. Stengel, N.P.M.M. van Lipzig, How well can a convection-permitting climate model reproduce decadal statistics of precipitation, temperature and cloud characteristics?, Clim. Dyn. 47 (2016) 3043-3061. doi:10.1007/s00382-0163012-z.

[44] S. Vanden Broucke, N. Van Lipzig, Do convection-permitting models improve the representation of the impact of LUC?, Clim. Dyn. 49 (2017) 2749-2763. doi:10.1007/s00382-016-3489-5.

[45] P. Termonia, B. Van Schaeybroeck, L. De Cruz, R. De Troch, S. Caluwaerts, O. Giot, R. Hamdi, S. Vannitsem, F. Duchêne, P. Willems, H. Tabari, E. Van Uytven, P. Hosseinzadehtalaei, N. Van Lipzig, H. Wouters, S. Vanden Broucke, J.P. van Ypersele, P. Marbaix, C. Villanueva-Birriel, X. Fettweis, C. Wyard, C. Scholzen, S. Doutreloup, K. De Ridder, A. Gobin, D. Lauwaet, T. Stavrakou, M. Bauwens, J.F. Müller, P. Luyten, S. 
Ponsar, D. Van den Eynde, E. Pottiaux, The CORDEX.be initiative as a foundation for climate services in Belgium, Clim. Serv. 11 (2018) 49-61. doi:10.1016/j.cliser.2018.05.001.

[46] S. Vanden Broucke, H. Wouters, M. Demuzere, N.P.M. van Lipzig, The influence of convection-permitting regional climate modeling on future projections of extreme precipitation: dependency on topography and timescale, Clim. Dyn. 52 (2019) 5303-5324. doi:10.1007/s00382-018-4454-2.

[47] H. Wouters, M. Demuzere, U. Blahak, K. Fortuniak, B. Maiheu, J. Camps, D. Tielemans, N.P.M. Van Lipzig, The efficient urban canopy dependency parametrization (SURY) v1.0 for atmospheric modelling: Description and application with the COSMO-CLM model for a Belgian summer, Geosci. Model Dev. 9 (2016) 3027-3054. doi:10.5194/gmd-9-3027-2016.

[48] K. De Ridder, B. Maiheu, H. Wouters, N. van Lipzig, Indicatoren van het stedelijk hitte-eiland in Vlaanderen, Vlaamse MilieuMaatschappij, 2015.

[49] D. Ramon, K. Allacker, N.P.M. van Lipzig, F. De Troyer, H. Wouters, Future Weather Data for Dynamic Building Energy Simulations: Overview of Available Data and Presentation of Newly Derived Data for Belgium, in: T.-E. Motoasca, A.K. Agarwal, H. Breesch (Eds.), Energy, Environ. Sustain., Springer, 2019: pp. 111-138. doi:10.1007/978-981-13-3284-5_6.

[50] A. Moazami, S. Carlucci, V.M. Nik, S. Geving, Towards climate robust buildings: An innovative method for designing buildings with robust energy performance under climate change, Energy Build. (2019). doi:10.1016/j.enbuild.2019.109378.

[51] V.M. Nik, A. Sasic Kalagasidis, Impact study of the climate change on the energy performance of the building stock in Stockholm considering four climate uncertainties, Build. Environ. 60 (2013) 291-304. doi:10.1016/j.buildenv.2012.11.005. 